\title{
Citologia Hormonal do Trato Urinário Baixo e da Vagina de Mulheres na Pós- menopausa, antes e durante Estrogenioterapia Oral e Transdérmica
}

\author{
Urinary and Vaginal Cytology of Postmenopausal Women with Oral and \\ Transdermal Estrogen Replacement
}

Áurea Belas Lustosa, Manoel João Batista Castello Girão, Marair Gracio Ferreira Sartori, Edmund Chada Baracat, Geraldo Rodrigues de Lima

\begin{abstract}
RESUM0
Objetivo: avaliar a ação dos estrogênios por via oral ou transdérmica nas células do trato urinário baixo e da vagina, em mulheres menopausadas.

Métodos: foram incluídas 25 mulheres na pós-menopausa, nas quais se estudaram os efeitos citológicos da terapia de reposição hormonal estrogênica, por via oral e por via transdérmica, sobre as células da vagina e do sedimento urinário. As pacientes foram distribuídas aleatoriamente em 2 grupos: Grupo I, constituido por 14 mulheres que receberam $0,625 \mathrm{mg}$ de estrogênio conjugado eqüino associado a $5 \mathrm{mg}$ de acetato de medroxiprogesterona, por via oral, diariamente sem intervalo por três meses, e Grupo II, formado por 11 mulheres que fizeram uso de 17-beta-estradiol matricial na dose de $50 \mu \mathrm{g}$, por via transdérmica, semanalmente, associado a $5 \mathrm{mg}$ de acetato de medroxiprogesterona diariamente por três meses. As amostras urinárias foram obtidas do jato inicial da primeira urina da manhã, após asseio dos genitais, em frascos estéreis fornecidos pelo laboratório. A urina foi centrifugada e o esfregaço realizado a partir do sedimento urinário. Os esfregaços da vagina e do sedimento urinário foram imediatamente fixados em álcool absoluto e corados pelo método de Shorr. Resultados: observou-se que nas pacientes que utilizaram a via oral, houve maturação das células da vagina (o índice se elevou de 45,4 a 65,5 com dois meses de tratamento, permanecendo praticamente constante $(62,0)$ a seguir. Quanto às células urinárias, não houve variação do valor de maturação (56,4 antes da medicação e 60,4 no final do período). Ao examinarmos tanto as células da urina quanto da vagina de pacientes que utilizaram a via transdérmica, notou-se que houve resposta satisfatória.

Conclusão: com estes resultados podemos sugerir que os estrogênios, quando administrados por via transdérmica, estão associados à resposta satisfatória quanto ao trofismo tanto na vagina quanto na uretra. No entanto, quando se utiliza a via oral, nem sempre este resultado pode ser observado.
\end{abstract}

PALAVRAS-CHAVE: Menopausa. Estrogenioterapia. Citologia Hormonal.

Introdução

Os sintomas genitais decorrentes do hipoestrogenismo incluem prurido vulvar, vagina seca e dispareunia e os urinários vão desde disúria e

Universidade Federal de São Paulo - Escola Paulista de Medicina- Departamento de Ginecologia e Ambulatório de Ginecologia da Santa Casa de Misericórdia do Estado do Pará

Correspondência: Marair G. F. Sartori

Av Onze de Junho, 1006 apto 51

04041-003 - São Paulo - SP polaciúria até infecção e incontinência ${ }^{1}$. Os efeitos do hipoestrogenismo no trato urinário encontram justificativa na embriogênese, pois tanto a vagina como a uretra distal têm origem embriológica comum, a partir do seio urogenital. Assim, ambas respondem à ação dos esteróides sexuais $^{2-6}$. Outro indicativo da sensibilidade do trato urinário inferior da mulher aos esteróides sexuais é a existência de receptores hormonais, fato comprovado por vários pesquisadores ${ }^{7}$. Sendo as mucosas vaginal e uretral sensiveis aos esteróides ovarianos, as células delas esfoliadas traduzem a 
ação desses hormônios, permitindo, por meio de sua análise, saber o estado funcional do ovário ${ }^{8-10}$. No climatério, observam-se esfregaços vaginais hipotróficos ou até acentuadamente atróficos ${ }^{10,11}$.

O esfregaço atrófico se caracteriza pela ausência de células superficiais eosinófilas e por porcentagem variável de células profundas. O grau de atrofia é tanto maior quanto maior a quantidade de células profundas encontradas no esfregaço ${ }^{8,9,12}$.

Dentre os vários índices que existem para classificar as influências hormonais no epitélio vaginal e urinário, os mais utilizados são o índice de maturação celular, o índice de cariopicnose e o de eosinofilia. Porém, dependem da variação citológica individual do epitélio e da interpretação pessoal de diferentes observadores ${ }^{8}$. $\mathrm{O}$ indice de maturação celular ou de Frost parece ser o mais informativo de todos e consiste na determinação de células profundas, intermediárias e superficiais $(\mathrm{P} / \mathrm{I} / \mathrm{S})$, expressas em porcentagem ${ }^{8-10}$.

O valor de maturação ou índice de Meisels é calculado a partir do índice de maturação celular, e corresponde ao somatório do número das células profundas multiplicadas por zero, do número de células intermediárias multiplicadas por meio e do número de células superficiais multiplicadas por um (profundas $\mathrm{x} 0+$ intermediárias $\mathrm{x} 0,5+$ superficiais $\mathrm{x} 1$ ), sendo mais utilizado para a comunicação entre citologistas e em trabalhos científicos, porém, não indicado para dar laudos citológicos destinados ao clínico ${ }^{8,9,13}$.

O índice de maturação sofre desvio à esquerda na pós-menopausa, com predomínio de células parabasais, situação que pode ser mudada com a administração de estrogênio. Sartori et al. ${ }^{14}$ analisaram os efeitos do estrogênio conjugado eqüino associado com o acetato de medroxiprogesterona por via oral na citologia urinária. Observaram aumento de células superficiais após três meses de reposição ${ }^{14}$. Faria ${ }^{15}$ observou índice de maturação vaginal maior nas pacientes que utilizaram tamoxifeno do que nas mulheres que não usaram qualquer medicamento hormonal. Já nos valores do índice de maturação das células urinárias, não observou diferença estatisticamente significante.

Este estudo tem por objetivo avaliar os aspectos citológicos de esfregaços vaginais e urinários de pacientes na pós-menopausa, de acordo com a via de administração de estrogênios.

\section{Pacientes e Métodos}

Selecionamos 25 pacientes na pós-menopausa atendidas no Ambulatório de Ginecologia da
Santa Casa de Misericórdia do Estado do Pará, no período de setembro de 1998 a abril de 2000. A idade das pacientes variou de 36 a 63 anos, com média de 54 anos.

Incluímos apenas pacientes com amenorréia por período superior a um ano, com níveis séricos de FSH, de LH e de estradiol compativeis com pós-menopausa e sem contra-indicação para o uso de reposição hormonal. Não foram incluídas pacientes que tinham utilizado medicação hormonal nos últimos 12 meses.

Todas foram informadas sobre o protocolo a ser adotado e assinaram termo de consentimento. O presente estudo foi aprovado pela Comissão de Ética das Instituições.

Realizou-se a ultra-sonografia endovaginal para avaliação da pelve e, em particular, do endométrio. Todas as pacientes incluídas tinham endométrio com no máximo $4 \mathrm{~mm}$ de espessura. Foram solicitados, também, exame de urina tipo I e urocultura antes do urocitograma inicial, sendo excluídos os casos com infecção urinária.

As pacientes foram distribuídas aleatoriamente em 2 grupos: Grupo I, constituído por 14 mulheres que receberam $0,625 \mathrm{mg}$ de estrogênio conjugado eqüino associado a $5 \mathrm{mg}$ de acetato de medroxiprogesterona, por via oral, diariamente sem intervalo por três meses, e Grupo II, formado por 11 mulheres que fizeram uso de 17-beta-estradiol matricial na dose de $50 \mu \mathrm{g}$, por via transdérmica, semanalmente, associado a $5 \mathrm{mg}$ de acetato de medroxiprogesterona diariamente por três meses.

Os grupos foram homogêneos quanto à idade, tempo de pós-menopausa e índice de massa corpórea (IMC).

As pacientes foram orientadas a evitar relação sexual, cremes, duchas, talcos e lavagens vaginais 48 horas antes das coletas. Utilizamos espéculo vaginal descartável sem lubrificantes, e o material foi colhido com espátula de madeira de Ayre do fórnice vaginal posterior e das paredes vaginais laterais.

As amostras urinárias foram obtidas do jato inicial da primeira urina da manhã, após asseio dos genitais, em frascos estéreis fornecidos pelo laboratório. A urina foi centrifugada e o esfregaço realizado a partir do sedimento urinário.

Os esfregaços da vagina e do sedimento urinário foram imediatamente fixados em álcool absoluto e corados pelo método de Shorr. As lâminas foram examinadas pela microscopia de luz, pelo mesmo citologista, utilizando ocular de 10 aumentos e objetiva de 10X para a avaliação inicial e, em seguida, procedeu-se à análise de 100 células com a mesma ocular e objetiva de 40X em campos escolhidos aleatoriamente. Fez-se a con- 
tagem percentual de cada tipo celular, ou seja, células profundas, intermediárias e superficiais (P/I/S), obtendo-se o índice de maturação celular ou índice de Frost, segundo descrito por Lencione ${ }^{9}$. Para viabilizar a análise estatística, calculou-se o indice de Meisels ou valor de maturação celular9,13.

Colhemos as citologias antes e após um, dois e três meses de reposição hormonal, constituindo, respectivamente, os tempos TO, T1, T2 e T3. Relacionamos os resultados citológicos entre os grupos, conforme as categorias seguintes: VO-VAG (colpocitograma das pacientes do Grupo I - estrogênio via oral); VO-URO (urocitograma das pacientes do Grupo I - estrogênio via oral); Trans-VAG (colpocitograma das pacientes do Grupo II - estrogênio transdérmico); Trans-URO (urocitograma das pacientes do Grupo II - estrogênio transdérmico).

Empregou-se a análise de dados longitudinais, com a finalidade de avaliar a resposta de maturação celular à administração de estrogênio e de progesterona por via oral e transdérmica, na mucosa da vagina e no sedimento urinário ao longo do tempo. Fixou-se em 5\% o nível de significância (alfa $=5 \%$ ), assinalando-se com asterisco os níveis descritivos (p) significantes.

\section{Resultados}

Os grupos foram homogêneos antes do início da reposição hormonal (TO) para a citologia vaginal e urinária.

$\mathrm{Na}$ Tabela 1 estão indicados os valores dos indices de maturação das células vaginais e urinárias nos tempos estudados, de acordo com a via de administração de estrogênios.

Tabela 1 - Valores de maturação das células vaginais (VAG) e urinárias (URO) dos grupos I (estrogênio oral - VO) e II (estrogênio transdérmico - Trans), consoante o tempo de reposição.

\begin{tabular}{|c|c|c|c|c|c|}
\hline Grupos & & TO & T1 & T2 & T3 \\
\hline I & $\begin{array}{c}\text { Células vaginais } \\
\text { (VO-VAG) }\end{array}$ & 45,4 & 62,1 & 65,5 & 62,0 \\
\hline I & $\begin{array}{c}\text { Células urinárias } \\
\text { (VO-URO) }\end{array}$ & 56,4 & 59,3 & 63,2 & 60,4 \\
\hline II & $\begin{array}{c}\text { Células vaginais } \\
\text { (Trans-VAG) }\end{array}$ & 47,3 & 67,3 & 65,7 & 59,5 \\
\hline II & $\begin{array}{c}\text { Células urinárias } \\
\text { (Trans-URO) }\end{array}$ & 52,5 & 62,7 & 61,4 & 58,4 \\
\hline
\end{tabular}

Quanto às células vaginais das pacientes do Grupo I, observamos aumento no valor do índice de maturação celular, que variou de 45,4 a 65,5 com dois meses de tratamento, permanecendo praticamente constante $(62,0)$ a seguir. Quanto às células urinárias, não houve variação do valor de maturação, sendo de 56,4 antes da medicação e 60,4 no final do periodo estudado.

Guando analisado o Grupo II, que recebeu estrogênios por via transdérmica, também encontramos aumento do valor de maturação tanto nas células vaginais quanto urinárias, com modificação dos valores de 47,3 para 59,5 e de 52,5 para 58,4 , respectivamente. (Tabela 1 e Figura 1).

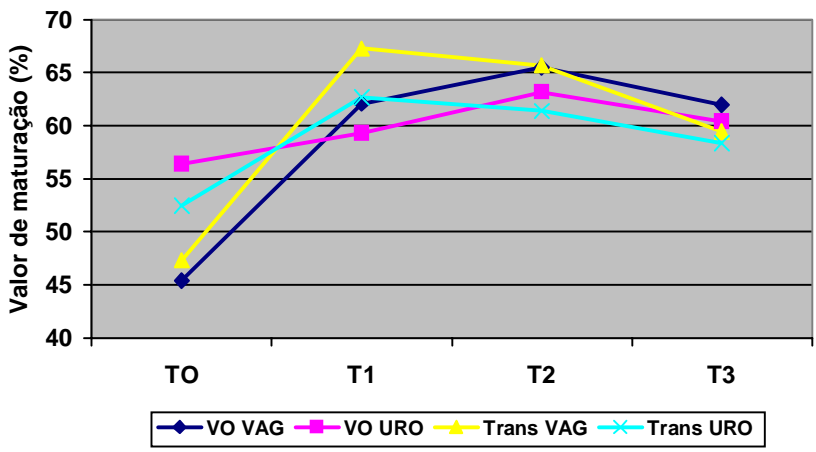

T0: pré-tratamento; T1: $1^{\circ}$ mês de tratamento; T2: $2^{\circ}$ mês de tratamento; T3: $3^{\circ}$ mês de tratamento.

Figura 1 - Valor de maturação (média) das células vaginais (VAG) e urinárias (URO) das pacientes dos Grupos I (estrogênio oral - VO) e II (estrogênio transdérmico - Trans), consoante o tempo de reposição

\section{Discussão}

Como exposto anteriormente, os estrogênios agem sobre o trofismo da mucosa uretral e vaginal, o tônus e o trofismo muscular, o tecido conjuntivo dos tratos urinário e genital e sobre a vascularização periuretral ${ }^{2}$.

Sabe-se que as alterações decorrentes do hipoestrogenismo são evitadas ou corrigidas com a reposição hormonal, porém o baixo grau de conhecimento, por parte das mulheres, a respeito dos benefícios desta terapia, associado ao medo dos seus efeitos colaterais incluindo o câncer, faz com que a paciente não aceite ou mesmo descontinue o tratamento, perdendo com isto qualidade de vida ${ }^{2}$.

Como se depreende do exposto, o impacto da deficiência estrínica sobre o trato urinário produz alterações significativas nos mecanismos de continência urinária e pode gerar vários sintomas, com evidente impacto na qualidade de vida da mulher neste período.

Em face dos parcos estudos avaliando os efeitos da reposição estrogênica nas células do sedimento urinário, assim como os resultados 
conflitantes e a ausência de comparação entre a via oral e a transdérmica, resolvemos realizar o presente estudo.

Diferente do encontrado por Sartori et al. ${ }^{14}$, que observaram aumento significativo de células superficiais e diminuição das células profundas após reposição com estrogênio conjugado eqüino e acetato de medroxiprogesterona por três meses, não notamos efeito significante sobre as células urinárias após administração de estrogênio por via oral.

Os nossos resultados coincidem com os relatados por Faria ${ }^{15}$ que, estudando os efeitos do tamoxifeno, modulador seletivo de receptor de estrogênio, sobre o trato urinário, não identificou diferença significativa na citologia hormonal da urina de pacientes na pós-menopausa que utilizavam este fármaco, comparadas com mulheres que não haviam feito uso de qualquer medicamento hormonal nos 12 meses anteriores.

Identificamos efeito significante sobre a citologia urinária apenas com o estrogênio transdérmico. Nestes casos notamos melhora do indice de maturação após o primeiro mês de tratamento, que se mantive constante após este período.

Interessante correlacionar estes achados com os relatos de Suguita et al. ${ }^{16}$ que realizaram estudo morfológico e morfométrico das mucosas vesical e uretral de ratas castradas, durante a reposição estrogênica e/ou progestacional, e registrou a presença de metaplasia, hiperplasia e aumento da espessura do epitélio do trato urinário baixo nas que receberam hormônios. Estes autores concluíram que a reposição estrogênica estimula a mucosa do trato urinário inferior tanto morfológica quanto morfometricamente. Somente com o estrogênio transdérmico, conseguimos reproduzir a proliferação do epitélio urinário observado neste trabalho experimental.

O fato de termos notado diferença na citologia vaginal em ambos os grupos, ou seja, tanto após estrogênio por via oral quanto por via transdérmica, garante que as pacientes utilizaram os medicamentos e que conseguimos produzir adequado estímulo estrogênico. Portanto, garante a confiabilidade dos dados obtidos na citologia urinária.

Em face do relatado podemos supor que o estímulo na mucosa do trato urinário inferior da mulher na pós-menopausa é maior após a utilização de estradiol por via transdérmica, do que com o estrogênio conjugado eqüino por via oral.

\section{ABSTRACT}

Objective: to study the effects of oral or transdermal estrogen replacement on the lower urinary tract and vagina in postmenopausal women

Methods: we studied 25 postmenopausal women evaluating the oral or transdermic estrogen replacement effects on the vaginal cells and urinary sediment during 3 months. The patients were randomly distributed into 2 groups: Group I, $n=14$, treated orally with $0.625 \mathrm{mg}$ equine conjugated estrogen plus $5 \mathrm{mg}$ medroxyprogesterone acetate, daily for 3 months; Group II, $n=11$, treated transdermally with $50 \mu \mathrm{g}$ 17- $\beta$-estradiol, once a week, plus 5 mg medroxyprogesterone. Daily, for 3 months, urinary samples were collected from the first miction in the morning after urogenital antisepsis into sterile tubes. The sample was centrifuged and the sediment was smeared. Vaginal and urinary smears were then fixed in absoluted alcohol and stained by the method of Shorr.

Results: the patients who used the oral route presented maturation of the vaginal cells (from 45.4 to $65.5 \%$ after 2 months of treatment, maintaing $62 \%$ afterwards) but this did not occur with urinary cells (56.4 before treatment versus $60.4 \%$ at the end of the period). The transdermal route promoted maturation of vaginal and urinary cells.

Conclusion: we have concluded that transdermal estrogens have satisfactory effects both on vaginal and urethral sites. However, with the oral route we did not find the expected results in the urinary tract in all cases.

KEY WORDS: Menopause. Estrogen therapy. Urinary tract. Hormonal cytology.

\section{Referências}

1. Schaffer J, Fantl JA. Urogenital effects of the menopause. Ballieres Clin Obstet Gynaecol 1996; 10:401-17

2. Baracat EC, Sartori MGF, Haidar MA, Girão MJBC, Rodrigues de Lima G. Alterações urogenitais no climatério. In: Girão MJBC, Rodrigues de Lima G, Baracat EC, editores. Uroginecologia. $1^{\text {a }}$ ed. São Paulo: Artes Médicas; 1997. p.91-8.

3. Sartori MGF, Girão MJBC, Simões MJ, Sartori JP, Baracat EC, Rodrigues de Lima G. Quantitative evaluation of collagen and muscle fibers in the lower urinary tract of castrated and under-hormone replacement female rats. Clin Exp Obstet Gynecol 2001; 28: 92-6.

4. Girão MJBC. Efeitos da reposição estrogênica nos parâmetros dopplervelocimétricos dos vasos periuretrais em mulheres na pós-menopausa com incontinência urinária de esforço [tese]. São Paulo: Universidade Federal de São Paulo; 1998.

5. Jármy-Di Bella ZIK, Girão MJBC, Sartori MGF, Di Bella V, Lederman H, Baracat EC, Lima GR. Power Doppler of the urethra in continent or urinary incontinent pre- and postmenopausal women. Int Urogynecol J Pelvic Floor Dysfunct 2000; 148-154, discussion 154-5. 
6. Endo RM, Girão MJBC, Sartori MGF, Simões MJ, Baracat EC, Rodrigues de Lima G. Effects of estrogen-progestogen hormonal replacement therapy on periurethral and bladder vessels. Int Urogynecol J Pelvic Floor Dysfunct 2000; 11:120-3.

7. Iosif CS, Batra S, Ek A, Astedt B. Estrogen receptors in the human female lower urinary tract. Am J Obstet Gynecol 1981; 141:817-20.

8. Wied GL, Bibbo M. Hormonal cytology. In: Bibbo M, editor. Comprehensive Cytopathology. $2^{\text {nd }}$ ed. New York: W.B. Saunders; 1997. p.101-24.

9. Lencioni LJ. Citologia endócrina. $1^{\mathrm{a}}$ ed. Buenos Aires: Médica Pan Americana; 1987.

10. Rodrigues DC, Silva IF. Colpocitologia funcional. In: Medina J, Salvatore CA, Bastos AC, editores. Propedêutica Ginecológica. $3^{\mathrm{a}}$ ed. São Paulo: Manole; 1977. p.159-74.

11.Silva IF. Urocitograma. In: Medina J, Salvatore CA, Bastos AC, editores. Propedêutica Ginecológica. $3^{\text {a }}$ ed. São Paulo: Manole; 1977. p.175-84.

12. Carvalho G. Estudo das distintas fases do ciclo sexual normal por meio do conteúdo celular encontrado na cavidade vaginal. Estudo de outros tipos de esfregaços, diferentes dos observados no ciclo menstrual normal e relacionados ou não com atividade hormonal. Citologia do trato genital feminino. $3^{\text {a }}$ ed. São Paulo: Atheneu; 1993. p.149-95.

13. Meisels A. The maturation value. Acta Cytol 1967; 11:249-55.

14.Sartori MGF, Baracat EC, Girão MJBC, Gonçalves WJ, Sartori JP, Lima GR. Menopausal genuine stress urinary incontinence treated with conjugated estrogens plus progestogens. Int $\mathrm{J}$ Gynaecol Obstet 1995; 49:165-9.

15.Faria CA. Efeitos do tamoxifeno sobre as citologias vaginal e urinária e a dopplervelocimetria dos vasos peri-uretrais de mulheres na pós-menopausa [tese]. São Paulo: Universidade Federal de São Paulo; 2000.

16.Suguita M, Girão MJBC, Simões MJ, Sartori MGF, Baracat EC, Rodrigues de Lima G. A morphologic and morphometric study of the vesical mucosa and urethra of castrated female rats following estrogen and/or progestogen replacement. Clin Exp Obstet Gynecol 2000; 27:176-8.

\title{
XVII Congresso Mundial de Ginecologia e O bstetrícia
}

\section{2 a 07 de novembro de 2003}

\section{Santiago - Chile}

\author{
Informações: \\ FIGO \\ (514) 286-0855 - 286-6066 \\ figo2003@eventsintl.com
}

